\section{Drs. Fisher and Cronstein reply}

\section{To the Editor:}

We read with interest Ranganathan and McLeod's comments and agree with their conclusions. We carried out our metaanalysis ${ }^{1}$ of the association of single-nucleotide polymorphisms (SNP) in the methylenetetrahydrofolate reductase (MTHFR) gene with methotrexate (MTX) toxicity because of the extremely poor reproducibility of small candidate gene studies ${ }^{2}$, as noted by Ranganathan. Also, as noted by Ranganathan and McLeod, proper racial and ethnic stratification is essential in genetic association studies, and the studies we reviewed were not well stratified. We also agree that larger studies with appropriate stratification for race and ethnicity will help clarify MTX pharmacogenetics.

It should also be noted, as we discussed, that MTX "toxicity" covers many conditions (pulmonary difficulties, hepatic fibrosis, anemia, nausea and vomiting, sleepiness), which are not likely due to a single genetic cause, rendering the demonstration that "toxicity" is associated with a specific genotype even more difficult.

Finally, all patients with rheumatoid arthritis are taking a number of different drugs including nonsteroidal antiinflammatory drugs, corticosteroids, various monoclonal antibodies, sulfasalazine, and hydroxychloro- quine, not to mention drugs for other common conditions like hypertension. The interaction of these other drugs with MTX and the genetic predisposition to these interactions has not been well evaluated, and the studies carried out to date cannot even begin to approach this problem.

MARK FISHER, MD, MPH, Rheumatology, New York University Hospital for Joint Diseases, 301 E. 17th St., New York, New York 10003, USA; BRUCE CRONSTEIN, MD, New York University, 550 First Ave., NBV16N1 New York, New York 10024, USA. Address correspondence to Dr. Fisher. E-mail: markcfisher@gmail.com

\section{REFERENCES}

1. Fisher MC, Cronstein BN. Metaanalysis of methylenetetrahydrofolate reductase (MTHFR) polymorphisms affecting methotrexate toxicity. J Rheumatol 2009;36:539-45.

2. Hirschhorn JN, Lohmueller K, Byrne E, Hirschhorn K. A comprehensive review of genetic association studies. Genet Med 2002;4:45-61.

J Rheumatol 2010;37:5; doi:10.3899/jrheum.091312 